\title{
BOYUTSAL KARARLILIK BAĞLAMINDA AHŞAP MALZEMEDE GÖZENEK DOLDURMA İŞLEMININ KOŞULLU OLASILIK İLE DEĞERLENDİRILMESİ
}

\section{İlker USTA*}

\begin{abstract}
ÖZET
Doğal ve organik bir malzeme olan ahşabın boyutsal kararlılığı, kullanım yeri koşullarının etkisiyle zamanla açığa çıkan hacimsel daralma ve hacimsel genişleme eğilimine karşı, kurutma işlemine ilaveten emprenye ve/veya cila işlemleri uygulanmak suretiyle ortaya koyulan boyut değişmezliğine temellenir. Genel anlamıyla bakıldığında, doğal malzemelerle özdeşleşmiş bir davranış hassasiyeti olan boyutsal kararlılık, birim ölçüye dayalı mesafelerin farklılaşmasıyla gün yüzüne çıkan boyut değişiminin uygun yöntemlerle sınırlandırılmasıyla temin edilebilen bir içselliğe sahiptir. Bu çerçevede, boyutsal kararlılık veya boyut değişmezliği, öngörülen kullanım amacı kapsamında uzun süreli bir etkinlikle ahşabın kullanılabilmesi için, ahşap malzemenin bir ürüne dönüştürülmesi öncesinde çözümlenmesi gerekli görülen önemli bir husus olarak değerlendirilir. Buna göre, bu çalışmada, gözenek doldurma işlemi odağında, ahşap malzemenin hacimsel daralma ve hacimsel genişleme nezdinde gösterdiği boyutsal kararlılığının, birinin diğerine bağlı olduğu sıralı bir süreç olarak birbirlerini etkilemesi mahiyetinde, koşullu olasılık yaklaşımı ile istatistiksel açıdan değerlendirilmesi amaçlanmıştır.
\end{abstract}

Anahtar Kelimeler: Ahşap, Boyutsal Kararlılık, Üst Yüzey İşlemleri, Gözenek Doldurma, Koşullu Olasılık.

JEL Kodları: C13, Q29.

\section{EVALUATION OF PORE FILLING IN WOOD MATERIAL WITH CONDITIONAL PROBABILITY IN THE CONTEXT OF DIMENSIONAL STABILITY}

\begin{abstract}
The dimensional stability of wood, which is a natural and organic material, is based on the size constancy revealed by the application of impregnation and/or polishing processes in addition to the drying process, against the tendency of both volumetric shrinkage and volumetric swelling that occurs over time with the effect of the conditions of use. In general terms, dimensional stability, which is a behavioral sensitivity identified with natural materials, has an internality that can be obtained by limiting the size change that emerges with the differentiation of distances based on unit measure, with appropriate methods. In this context, dimensional stability or dimensional invariance is considered an important issue that needs to be resolved before wood material is converted into a product, so that wood can be used with long-term effectiveness for its intended use. Accordingly, in this study, it is aimed to statistically evaluate the dimensional stability of wood material in terms of volume contraction and volume expansion at the focus of the pore filling process, as they affect each other as a sequential process, one of which is dependent on the other, with the conditional probability approach.
\end{abstract}

Keywords: Wood, Dimensional Stabilization, Surface Treatments, Pore Filling, Conditional Probability.

JEL Codes: C13, Q29.

Hacettepe Üniversitesi, , Ağaç İşleri Endüstri Mühendisliği Bölümü, Prof.Dr., iusta@hacettepe.edu.tr 


\section{TÜRKIYE MESLEKI VE SOSYAL BILIMLER DERGISI}

Türkiye Mesleki ve Sosyal Bilimler Dergisi, Aralık 2021, Yıl: 3, Sayı: 7, 74-81

Journal of Vocational and Social Sciences of Turkey, Dec 2021, Year: 3, No: 7, 74-81.

\section{GİRIŞ}

Ahşap malzeme için, doğal ve organik içselliği ile lifli ve gözenekli yapısından ötürü, niteleyici bir nicelik durumu olan boyutsal kararlılık, lif doygunluğu noktası altındaki rutubet miktarı temel teşkil etmek üzere, hacimsel daralma ve hacimsel genişleme bağlamında, ahşabın kullanım yeri ile kullanılma şekline doğrudan veya dolaylı biçimde etkide bulunan önemli bir husus olup ahşabın anizotropik daralma ve genişleme özelliği dikkate alınarak, emprenye (ahşap koruma) zemininde, kurutma işlemi ve üst yüzey işlemleriyle bütünleşik bir hazırlama sürecini içeren iş ve işlemler yordamıla temin edilmeye çalışılır ve bu meyanda boyut değişiminin eleminasyonu ya da sınırlandırılması amaçlanır (Usta, 2016). Ahşabın boyut değişmezliğine sahip olması, ahşap işleme faaliyetlerinin ana eksenini oluşturmaktadır (Usta, 2018). Mesela, estetik bir görünüm sağlamak üzere, perdah yordamıla esaslı bir şekilde gerçekleştirilen cila işlemi, güzellik pekiştirmesi ile ahşap malzemeye albeni kazandırmayı amaçlayan bir uygulama olup (Sönmez, 2000), cilalama öncesinde pürüzsüz bir yüzeyin meydana getirilmesi maksadıyla yapılan gözenek doldurma işlemi, düzgün ve tekdüze bir yapıya sahip bir üst yüzey oluşturma çabasıyla ayrılmaz bir bütünlük teşkil eder (Şanıvar, 1978). Bu çerçevede, değişik teknikler kullanılarak farklı gereçlerle gerçekleştirilen öncel bir üst yüzey işlemi olan gözenek doldurma işlemi, aynı zamanda ahşap malzemenin boyutsal kararlılığına katkı yapan bir uygulama olarak değerlendirilebildiğinden, gözenek doldurma işleminin ahşabın daralma ve/veya genişleme özelliği itibariyle boyutsal kararlılığına etkisi, bu çalışmada, istatistiki açıdan koşullu olasılık yaklaşımıyla örnek bir problem kapsamında takdim edilmiştir.

\section{1. ÖRNEK PROBLEM}

İçsel doğal yapısı itibariyle, gözeneklilik mevcudiyetine binaen, lif yoğunluğu az (gözenekliliği fazla) ve lif yoğunluğu fazla (gözenkliliği az) olan iki ağaç türünden temin edilen ahşap deney numuneleri, ölçüsel olarak $25 \times 25 \mathrm{~mm}$ enine kesit ve $50 \mathrm{~mm}$ uzunluğunda hazırlanarak, $20 \pm 2{ }^{\circ} \mathrm{C}$ ve $\% 65 \pm 5$ bağıl nem ortamında üç hafta süreyle bekletilmek suretiyle \%12 hava kurusu rutubet miktarına kadar kurutulup koşullandırıldıktan sonra, aşağıda belirtilen deneysel süreçlere göre sayıca ve çeşitçe gruplanıp işlenmek suretiyle boyutsal kararlılık durumu bakımından değerlendirilmiştir.

\subsection{Numune Hazırlama ve Deneysel Süreç}

Deneklerin yarısı, selülozik esaslı (kısmi geçirgen) bir dolgu gereci kullanılarak işlem-zımpara-işlem sırasıyla tüm yüzeylerine uygulanan sıvazlama işlemi vasıtasıyla gerçekleştirilen gözenek doldurma muamelesiyle hazırlanıp test edilirken, diğerleri ise rutubetlilik açısından (ortama göre içerdikleri nemlilik düzeyleri dahilinde evirilme serbestlikleriyle) \%12-15 arasındaki denge rutubeti mahiyetinde, mevcut hallerinde bırakılarak herhangi bir üst yüzey işlemi yapılmaksızın teste tabi tutulmuştur.

Numunelerin daralma ve genişleme tesiri karşısında ortaya koydukları boyutsal kararlılıklarının belirlenmesi için, üst yüzey işlemiyle gözeneklerinin doldurulması bağlamında ön hazırlık yapılanlar ile hiç hazırlama yapılmaksızın mevcut halleriyle bırakılanlar, yarı yarıya olmak üzere, nemlendirerek 1slatma ve rüzgarlayarak kurutma işlemlerinden geçirilerek (birer saatlik normal koşulları içeren geçişlerle 180 dakikalık sekizer çevrimli deneysel süreçler nezdinde) laboratuvar ortamında gerçekleştirilen yapay şartlandırmayla ayrıştırılmıştır. Bu kapsamda, numuneler; hacimsel genişleme değişimi için, $25^{\circ} \mathrm{C}$ sıcaklık ve $\% 75$ bağ 1 nem altında bekletilirken, hacimsel daralma değişimi için ise $3,5 \mathrm{~m} / \mathrm{dk}$ hava akımı etkisine maruz bırakılmıştır. Söz konusu hazırlama süreci çerçevesinde, numunelerin boyutları (uzunluk-genişlik-kalınlık mahiyetinde) hem ıslanma ve kurulanma işlemleri öncesinde hem de bu işlemlerin sonrasında dijital göstergeli kumpas vasıtasıyla ölçülmüş, boyutlarda meydana gelen artış veya azalış değişimi not edilerek, boyut değişmezliğine yaslanan boyutsal kararlılık başarısının açığa çıkarılarak koşullu olasılık açısından irdelenmesi öngörülmüştür. 


\section{2. ÇÖZÜMLEME}

Koşullu olasılık; Demirhan ve Hamurkaroğlu (2016) tarafından açıklandığı gibi, bir A olayının gerçekleşmesi halinde, bir $\mathrm{B}$ olayının meydana gelmesi ihtimali olup $\mathrm{P}(\mathrm{AuB})=\mathrm{P}(\mathrm{A})+\mathrm{P}(\mathrm{B})-\mathrm{P}(\mathrm{AnB})$ eşitliğiyle ifade edilir. Buna göre, $A$ ve $B$ birbirine bağlı ise; $P(A n B)=P(A) \times(P(B)$ eşitliğiyle hesaplanırken, $A$ ve $B$ birbirlerine bağlı ise; $\mathrm{P}(\mathrm{AnB})=\mathrm{P}(\mathrm{A}) \times \mathrm{P}(\mathrm{B} / \mathrm{A})$ eşitliğiyle hesaplanır. Burada, $\mathrm{P}(\mathrm{B} / \mathrm{A})$ ifadesi, A'nın gerçekleştiği varsayımıyla B'nin gerçekleşme olasılığını gösterir, yani A'nın gerçekleşip gerçekleşmemesi B'yi etkileyeceği için, $\mathrm{P}(\mathrm{B} / \mathrm{A})=\mathrm{P}(\mathrm{AnB}) / \mathrm{P}(\mathrm{A})$ eşitliğiyle şartlı (koşullu) olarak tespit edilir. Bu bağlamda, iki yönlü kıyaslama olarak, bu durum $\mathrm{B}$ için ele alınacak olursa, $\mathrm{P}(\mathrm{AnB})=\mathrm{P}(\mathrm{B}) \times \mathrm{P}(\mathrm{A} / \mathrm{B})$ ile $\mathrm{P}(\mathrm{A} / \mathrm{B})=\mathrm{P}(\mathrm{AnB}) / \mathrm{P}(\mathrm{B})$ eşitliği yazılabilir ve $\mathrm{B}$ 'nin gerçekleşmesi halinde A'nın gerçekleşmesinin mümkün olacağı söylenir. Öte yandan, bir konu hakkında üç olay veya durum bulunduğunda, bunlar birbirine bağlı değil ise, $\mathrm{P}(\mathrm{AnBnC})=\mathrm{P}(\mathrm{A}) \times \mathrm{P}(\mathrm{B}) \times \mathrm{P}(\mathrm{C})$ ile belirlenirken, bunlar birbirlerine bağlı ise, $\mathrm{P}(\mathrm{AnBnC})=\mathrm{P}(\mathrm{A}) \times \mathrm{P}(\mathrm{B} / \mathrm{A}) \times \mathrm{P}(\mathrm{C} / \mathrm{AxB})$ eşitliğiyle hesaplanır. Buradaki $\mathrm{P}(\mathrm{C} / \mathrm{AxB})$ ifadesi, $\mathrm{A}$ ve $\mathrm{B}$ gerçekleştiği takdirde C'nin gerçekleşmesinin düşünülebileceğini gösterir. Kobu (1987)'ya göre, birbirleri arasında ilişkiler bulunan olayları ihtiva eden karmaşı sistemlerde mevzubahis olabilecek olasılıklar, söz konusu olayların gerçekleşmesine sebebiyet veren süreçte yer alan aşamaların sonuçlarına bağlı olduğu için, ağaç diyagramı oluşturulmak suretiyle yapılan koşullu olasılık hesaplamaları kolaylaşır.

Buna göre, gözlem ve deney verilerine dayalı bulgularla, yukarıdaki örnek problem, halihazırdaki deneme deseni için bir örneklendirme ve çıkarsama yapmayı teminen, mevcut numuneler arasından rastgele seçilen denekler mahiyetinde; a) 89'u ön işlemli (gözenek doldurma muamelesi yapılmış) ve 81'i hazırlıksız (gözenek doldurma işlemi yapılmamış) olmak üzere toplam 170 numunenin test edildiği başarı durumu, "bütünleșik kıyaslama" temasıyla irdelenirken, b) daralma ve genişleme deneylerinden eşit sayıda seçilmek suretiyle, 107'si az yoğunluklu ve 102'si fazla yoğunluklu olmak üzere toplam 209 numunenin (gözenekliliği yansitan liflilik durumunun temel göstergesi olan) yoğunluk farklılığının boyutsal değişime sebebiyet veren muhtemel etkisi, "yoğunluk karşılaştırması" temasiyla irdelenmiş, c) 120'si genişleme ve 180'i daralma olmak üzere toplam 300 numunenin (ideal kararlılık sınırı veya eşik değer hüviyetiyle öne çıkarılmış olan maksimum yüzde beşlik değişim miktarı itibariyle) hacimsel bakımdan daralma veya genişleme biçiminde kendini gösteren boyutsal değişim, "ağaç diyagramı ile daralma ve genişleme karşılaştırması" temasıyla irdelenmiştir.

Bu perspektifte, elde edilen veriler, mümkün olan her açıdan bakılarak, koşullu olasılık veya diğer bir deyişle "şartlı ihtimal" yaklaşımıyla detaylıca incelenmiştir.

\subsection{Bütünleşik Kıyaslama}

Gerçekleştirilen daralma ve genişleme deneyleriyle elde edilen boyutsal kararlılık durumu, rastgele seçilen numuneler itibariyle, "test başarı durumu" hüviyetiyle Tablo 1'de gösterilmiştir.

Tablo 1. Genel Boyutsal Kararlılık Başarısı

\begin{tabular}{|c|c|c|c|}
\hline \multirow{2}{*}{ Ön İşlem } & \multicolumn{3}{|c|}{ Test Başarı Durumu } \\
\cline { 2 - 4 } & $\begin{array}{c}\text { Geçti } \\
(\mathbf{G})\end{array}$ & $\begin{array}{c}\text { Kaldı } \\
(\mathbf{K})\end{array}$ & Toplam \\
\hline Var & 64 & 25 & 89 \\
$(\mathbf{V})$ & $(\mathrm{Gv})$ & $(\mathrm{Kv})$ & $(\mathrm{Vt})$ \\
\hline Yok & 23 & 58 & 81 \\
$(\mathbf{Y})$ & $(\mathrm{Gy})$ & $(\mathrm{Ky})$ & $(\mathrm{Yt})$ \\
\hline \multirow{2}{*}{ Toplam } & 87 & 83 & 170 \\
& $(\mathrm{Gt})$ & $(\mathrm{Kt})$ & $(\mathrm{T})$ \\
\hline
\end{tabular}

Tesadüfi olarak seçilen numunelerin boyutsal kararlılık başarısı, Tablo 1'de gösterilen veriler bağlamında, koşullu olasılık hesaplamalarıyla aşağıdaki gibi değerlendirilmiştir. 
Numunelerin tamamının testi geçmesi olasılı̆̆ (başka bir ifadeyle, tüm numunelerin boyutsal kararlılığ sağlaması olasılığı), P(G) $=\mathrm{P}(\mathrm{Gt}) / \mathrm{P}(\mathrm{T})$ eşitliği ile $(87 / 170)=0,512$ (veya \%51,2) olarak belirlenirken, tüm numunelerin boyutsal kararlılık testinde başarılı olamaması olasıllı̆g ise, $\mathrm{P}(\mathrm{K})=$ $\mathrm{P}(\mathrm{Kt}) / \mathrm{P}(\mathrm{T})$ eşitliği ile $(83 / 170)=0,488$ (veya \%48,8) olarak belirlenmiştir. Bu değer, koşullu olasılık yaklaşımına göre "bütün olasılığı" ilkesi kapsamında, $\mathrm{P}=(1-\mathrm{s})$ eşitliği uyarınca, $\mathrm{P}(\mathrm{K})=1$ $\mathrm{P}(\mathrm{G})$ eşitliği ile $1-0,512=0,488$ (veya $\% 48,8$ ) olarak ayrıca hesaplanabilmektedir.

Ön işlem olarak addedilen gözenek doldurma işleminin tüm numunelerin boyutsal kararlılık başarısını etkilemesi olasıllı̆ı, $\mathrm{P}(\mathrm{V})=\mathrm{P}(\mathrm{Vt}) / \mathrm{P}(\mathrm{T})$ eşitliği ile $(89 / 170)=0,524$ (veya \%52,4) olarak hesaplanırken, ön işlem yapılmamasının boyutsal kararlılığı etkilemesi olasılığı ise, $\mathrm{P}(\mathrm{Y})=\mathrm{P}(\mathrm{Yt})$ / $\mathrm{P}(\mathrm{T})$ eşitliği ile $(81 / 170)=0,476$ (veya \%47,6) olarak hesaplanmıştır.

Gözenek doldurma işlemi yapılan numunelerin boyutsal kararlılık testinden geçmesi olasılı̆̆, $\mathrm{P}(\mathrm{GnV})$ $=\mathrm{P}(\mathrm{Gv}) / \mathrm{P}(\mathrm{T})$ eşitliği ile $(64 / 170)=0,376$ (veya \%37,6) olarak tespit edilirken, ön işlem yapılmamış numunelerin boyutsal kararlılık testinden kalması olasılığı ise, $\mathrm{P}(\mathrm{KnY})=\mathrm{P}(\mathrm{Ky}) / \mathrm{P}(\mathrm{T})$ eşitliği ile (58 / $170)=0,341$ (veya \%34,1) olarak tespit edilmiştir.

Ön işlem yapılmış bir numunenin boyutsal kararlı1ık testinden geçmesi olasılı̆̆ı, $\mathrm{P}(\mathrm{Gv} / \mathrm{Vt})=\mathrm{P}(\mathrm{Gv})$ / $\mathrm{P}(\mathrm{Vt})$ eşitliği ile $(64 / 89)=0,719$ (veya \%71,9) olarak belirlenirken, bu testten kalması olasıllğı ise, $\mathrm{P}(\mathrm{Kv} / \mathrm{Vt})=\mathrm{P}(\mathrm{Kv}) / \mathrm{P}(\mathrm{Vt})$ eşitliği ile $(25 / 89)=0,281$ (veya \%28,1) olarak belirlenmiştir.

Boyutsal kararlılık testinden geçmiş bir numunenin ön işlem yapılmış olması olasılığı, $\mathrm{P}(\mathrm{Gv} / \mathrm{Gt})=$ $\mathrm{P}(\mathrm{Gv}) / \mathrm{P}(\mathrm{Gt})$ eşitliği ile $(64$ / 87) = 0,736 (veya \%73,6) olarak hesaplanırken, bu testten geçmiş bir numunenin ön işlem yapılmamış olması olasılığı ise, $\mathrm{P}(\mathrm{Gy} / \mathrm{Gt})=\mathrm{P}(\mathrm{Gy}) / \mathrm{P}(\mathrm{Gt})$ eşitliği ile $(23 / 87)=$ 0,264 (veya \%26,4) olarak hesaplanmıştır.

Ön işlem yapılmamış bir numunenin boyutsal kararlılık testinden geçmesi olasılığ, $\mathrm{P}(\mathrm{Gy} / \mathrm{Yt})=$ $\mathrm{P}(\mathrm{Gy}) / \mathrm{P}(\mathrm{Yt})$ eşitliği ile $(23 / 81)=0,284$ (veya \%28,4) olarak tespit edilirken, bu testten kalmas1 olasılığı (boyutsal kararlılık testinden kalmış bir numunenin ön işlem yapılmamış olması olasılığı) ise, $\mathrm{P}(\mathrm{Ky} / \mathrm{Yt})=\mathrm{P}(\mathrm{Ky}) / \mathrm{P}(\mathrm{Yt})$ eşitliği ile $(58 / 81)=0,716$ (veya \%71,6) olarak tespit edilmiştir.

\subsection{Yoğunluk Karşılaştırması}

Birim hacimdeki liflilik düzeyi itibariyle yoğunluk farklılığı ihtiva eden numunelerin, gözenek doldurma işlemine tabi tutulup tutulmadıklarına göre, rastgele seçilmiş numunelerin daralma ve genişleme bakımından ortaya koydukları boyutsal kararlılık verileri Tablo 2'de gösterilmiştir.

Tablo 2. Yoğunluk Farklılığına Göre Boyutsal Kararlılık Durumu

\begin{tabular}{|c|c|c|c|c|c|}
\hline \multirow{2}{*}{ Yoğunluk } & \multicolumn{2}{|c|}{$\begin{array}{l}\text { Daralma } \\
\text { (D) }\end{array}$} & \multicolumn{2}{|c|}{$\begin{array}{c}\text { Genişleme } \\
\text { (G) }\end{array}$} & \multirow{2}{*}{ Toplam } \\
\hline & $\begin{array}{c}\text { Muamele } \\
\text { (M) }\end{array}$ & $\begin{array}{c}\text { Hazirlıksız } \\
(\mathrm{H})\end{array}$ & $\begin{array}{c}\text { Muamele } \\
\text { (M) }\end{array}$ & $\begin{array}{c}\text { Hazırlıksız } \\
(\mathrm{H})\end{array}$ & \\
\hline $\begin{array}{l}\mathbf{A z} \\
\text { (A) }\end{array}$ & $\begin{array}{c}16 \\
(\mathrm{dMa})\end{array}$ & $\begin{array}{c}34 \\
(\mathrm{dHa})\end{array}$ & $\begin{array}{c}18 \\
(\mathrm{gMa})\end{array}$ & $\begin{array}{c}39 \\
(\mathrm{gHa})\end{array}$ & $\begin{array}{l}107 \\
\text { (aT) }\end{array}$ \\
\hline $\begin{array}{c}\text { Fazla } \\
\text { (F) }\end{array}$ & $\begin{array}{c}17 \\
\text { (dMf) }\end{array}$ & $\begin{array}{c}38 \\
(\mathrm{dHf})\end{array}$ & $\begin{array}{c}14 \\
\text { (gMf) }\end{array}$ & $\begin{array}{c}33 \\
(\mathrm{gHf})\end{array}$ & $\begin{array}{l}102 \\
\text { (fT) }\end{array}$ \\
\hline \multirow{2}{*}{ Toplam } & $\begin{array}{c}33 \\
(\mathrm{dMT})\end{array}$ & $\begin{array}{c}72 \\
(\mathrm{dHT})\end{array}$ & $\begin{array}{c}32 \\
(\mathrm{gMT})\end{array}$ & $\begin{array}{c}72 \\
(\mathrm{gHT})\end{array}$ & \multirow{2}{*}{$\begin{array}{l}209 \\
(\mathrm{~T})\end{array}$} \\
\hline & \multicolumn{2}{|c|}{$\begin{array}{l}105 \\
\text { (dT) }\end{array}$} & \multicolumn{2}{|c|}{$\begin{array}{c}104 \\
\text { (gT) }\end{array}$} & \\
\hline
\end{tabular}

Rastgele seçilen farklı yoğunluklara sahip numunelerin, daralma ve genişleme bakımından ortaya koydukları boyutsal kararlılık başarısı, Tablo 2'de gösterilen veriler 1şı̆̆ında, koşullu olasılık hesaplamaları ile aşağıdaki gibi değerlendirilmiştir. 


\section{TÜRKIYE MESLEKI VE SOSYAL BILIMLER DERGISI}

Türkiye Mesleki ve Sosyal Bilimler Dergisi, Aralık 2021, Yıl: 3, Sayı: 7, 74-81

Journal of Vocational and Social Sciences of Turkey, Dec 2021, Year: 3, No: 7, 74-81.

Mevcut numunelerin fazla yoğunluklu olması olasılı̆̆, $\mathrm{P}(\mathrm{F})=[\mathrm{P}(\mathrm{dMf})+\mathrm{P}(\mathrm{dHf})+\mathrm{P}(\mathrm{gMf})+\mathrm{P}(\mathrm{gHf})] /$ $\mathrm{P}(\mathrm{T})$ eşitliği ile $[17+38+14+33] / 209=0,488$ (veya \%48,8) olarak tespit edilirken, az yoğunluklu olması olasılığı ise, $\mathrm{P}=(1-\mathrm{s})$ eşitliği uyarınca, $\mathrm{P}(\mathrm{A})=1-\mathrm{P}(\mathrm{F})$ eşitliği ile $1-0,488=0,512$ (veya $\% 51,2$ ) olarak hesaplanmıştır.

Numunelerin gözenek doldurma işlemi mahiyetinde ön işlem yapılmak suretiyle muamale edilmiş olması olasıllı̆ $1, \mathrm{P}(\mathrm{M})=[\mathrm{P}(\mathrm{dMa})+\mathrm{P}(\mathrm{dMf})+\mathrm{P}(\mathrm{gMa})+\mathrm{P}(\mathrm{gMf})] / \mathrm{P}(\mathrm{T})$ eşitliği ile $[16+17+18+14] /$ $209=0,311$ (veya $(\% 31,1)$ olarak belirlenirken, hazırlıksı (ön işlemle muamele edilmemiş) olması olasılığı ise, $\mathrm{P}=(1-\mathrm{s})$ eşitliği uyarınca, $\mathrm{P}(\mathrm{H})=1-\mathrm{P}(\mathrm{M})$ eşitliği ile $1-0,311=0,689$ (veya \%68,9) olarak tespit edilmiştir.

Muamele edilmiş bir numunenin az yoğunluklu olması olasılığ $[\mathrm{P}(\mathrm{dMT})+\mathrm{P}(\mathrm{gMT})]$ eşitliği ile $(16+18) /(33+32)=0,523$ (veya \%52,3) olarak belirlenirken, ön işlemle muamele edilmemiş bir numunenin fazla yoğunluklu olması olasılığ 1 ise, $P=(1-\mathrm{s})$ eşitliği uyarınca, 1 - P(Mf) eşitliği ile 1 - 0,523 = 0,477 (veya 47,7) olarak hesaplanmıştır.

Hazırlıksız bir numunenin fazla yoğunluklu olması olasılı̆̆, $\mathrm{P}(\mathrm{Hf})=[\mathrm{P}(\mathrm{dHf})+\mathrm{P}(\mathrm{gHf})] / \mathrm{P}(\mathrm{dHT})+$ $\mathrm{P}(\mathrm{gHT})]$ eşitliği ile $(38+33) /(72+72)=0,493$ (veya \%49,3) hesaplanırken, hazırlık yapılmamış bir numunenin az yoğunluklu olması olasıllğı ise, $\mathrm{P}=(1-\mathrm{s})$ eşitliği uyarınca, $\mathrm{P}(\mathrm{Ha})=1-\mathrm{P}(\mathrm{Hf})$ eşitliği ile $1-0,493=0,507$ (veya 50,7) olarak belirlenmiştir.

Mevcut numunelerin boyutlarında daralma meydana gelmesi olasılığ $1, P(D)=[P(d M a)+P(d M f)+$ $\mathrm{P}(\mathrm{dHa})+\mathrm{P}(\mathrm{dHf})] / \mathrm{P}(\mathrm{T})$ eşitliği ile $[16+17+34+38] / 209=0,502$ (veya \%50,2) olarak hesaplanırken, numunelerin boyutlarında genişleme meydana gelmesi olasılığ ise, $\mathrm{P}(\mathrm{G})=[\mathrm{P}(\mathrm{gMa})+$ $\mathrm{P}(\mathrm{gMf})+\mathrm{P}(\mathrm{gHa})+\mathrm{P}(\mathrm{gHf})] / \mathrm{P}(\mathrm{T})$ eşitliği ile $[18+14+39+33] / 209=0,498$ (veya \%49,8) olarak belirlenmiştir.

Boyutlarında daralma meydana gelmiş bir numunenin tüm numuneler nezdinde muamele edilmiş olanlardan olması olasılığı, $\mathrm{P}(\mathrm{DM})=\mathrm{P}(\mathrm{dMT}) / \mathrm{P}(\mathrm{T})$ eşitliği ile $33 / 209=0,158$ (veya \%15,8) olarak tespit edilirken, boyutları daralmış bir numunenin ön işlem yapılmış olan diğer numuneler kapsamında muamele edilmiş olanlardan olması olasılığ, $\mathrm{P}\left(\mathrm{DM}_{1}\right)=\mathrm{P}(\mathrm{dMT}) /[\mathrm{P}(\mathrm{dMT})+\mathrm{P}(\mathrm{gMT})]$ eşitliği ile 33 / $(33+32)=0,508$ (veya $\% 50,8)$ olarak belirlenmiş olup söz konusu numunenin daralma gerçekleşmiş diğer numunelerden biri olması olasılığ ise, $\mathrm{P}\left(\mathrm{DM}_{2}\right)=\mathrm{P}(\mathrm{dMT}) / \mathrm{P}(\mathrm{dT})$ eşitliği ile $33 / 105=0,314$ (veya \%31,4) olarak bulunmuştur. Öte yandan, boyutlarında daralma meydana gelmiş bir numunenin tüm numuneler nezdinde hazırlıksız olanlardan olması olasılığ $1, \mathrm{P}(\mathrm{DH})=\mathrm{P}(\mathrm{dHT}) / \mathrm{P}(\mathrm{T})$ eşitliği ile 72 / $209=0,344$ (veya \%34,4) olarak belirlenirken, boyutları daralmış bir numunenin gözenek doldurma işlemine tabi tutulmamış diğer numuneler kapsamında hazırlıksız olması olasılı̆̆ $1, \mathrm{P}\left(\mathrm{DH}_{1}\right)=\mathrm{P}(\mathrm{dHT})$ / $[\mathrm{P}(\mathrm{dHT})+\mathrm{P}(\mathrm{gHT})]$ eşitliği ile $72 /(72+72)=0,500$ (veya \%50,0) olarak hesaplanmış olup söz konusu numunenin daralma gerçekleşmiş diğer numunelerden biri olması olasıllğı ise, $\mathrm{P}\left(\mathrm{DH}_{2}\right)=$ $\mathrm{P}(\mathrm{dHT}) / \mathrm{P}(\mathrm{dT})$ eşitliği ile 72 / $105=0,686$ (veya \%68,6) olarak tespit edilmiştir.

Boyutlarında genişleme meydana gelmiş bir numunenin tüm numuneler nezdinde muamele edilmiş olanlardan olması olasılığı, P(GM) $=\mathrm{P}(\mathrm{gMT}) / \mathrm{P}(\mathrm{T})$ eşitliği ile $32 / 209=0,153$ (veya \%15,3) olarak tespit edilirken, boyutları genişlemiş bir numunenin ön işlemli diğer numuneler kapsamında muamele edilmiş olanlardan olması olasıllı̆ $\breve{l}_{1} \mathrm{P}\left(\mathrm{GM}_{1}\right)=\mathrm{P}(\mathrm{gMT}) /[\mathrm{P}(\mathrm{gMT})+\mathrm{P}(\mathrm{dMT})]$ eşitliği ile 32 / $(32+33)$ $=0,492$ (veya \% 49,2) olarak belirlenmiş olup söz konusu numunenin genişleme gerçekleşmiş diğer numunelerden biri olması olasılı̆̆ ise, $\mathrm{P}\left(\mathrm{GM}_{2}\right)=\mathrm{P}(\mathrm{gMT}) / \mathrm{P}(\mathrm{gT})$ eşitliği ile $32 / 104=0,308$ (veya $\% 30,8)$ olarak bulunmuştur. Öte yandan, boyutlarında genişleme meydana gelmiş bir numunenin tüm numuneler nezdinde hazırlıksız olanlardan olması olasılığı, $\mathrm{P}(\mathrm{GH})=\mathrm{P}(\mathrm{gHT}) / \mathrm{P}(\mathrm{T})$ eşitliği ile 72 / 209 $=0,344$ (veya \%34,4) olarak belirlenirken, boyutları genişlemiş bir numunenin gözenek doldurma işlemine tabi tutulmamış diğer numuneler kapsamında hazırlıksız olması olasılığı, $\mathrm{P}\left(\mathrm{GH}_{1}\right)=\mathrm{P}(\mathrm{gHT})$ / $[\mathrm{P}(\mathrm{gHT})+\mathrm{P}(\mathrm{dHT})]$ eşitliği ile $72 /(72+72)=0,500$ (veya \%50,0) olarak tespit edilmiş olup bu numunenin genişleme gerçekleşmiş diğer numunelerden biri olması olasıllı̆̆ ise, $\mathrm{P}\left(\mathrm{GH}_{2}\right)=\mathrm{P}(\mathrm{gHT}) /$ $\mathrm{P}(\mathrm{gT})$ eşitliği ile 72 / $104=0,692$ (veya \%69,2) olarak hesaplanmıştır. 


\section{TÜRKIYE MESLEKI VE SOSYAL BILIMLER DERGISI}

Türkiye Mesleki ve Sosyal Bilimler Dergisi, Aralık 2021, Yıl: 3, Sayı: 7, 74-81

Journal of Vocational and Social Sciences of Turkey, Dec 2021, Year: 3, No: 7, 74-81.

\section{3. Ăgaç Diyagramı ile Daralma ve Genişleme Karşılaştırması}

Numunelerin daralma ve genişleme itibariyle ortaya koydukları boyutsal kararlılık durumu, gözenek doldurma işlemiyle muamele edilip edilmemeyi içeren hazırlık süreci temelinde nedensel bir karşılaştırma yapmaya olanak sağlamak üzere, boyutlardaki artış veya azalış değişiminin en çok \%5 olmasının eşik değer kabul edilmesine atfen, esaslı bir sınama önermesi mahiyetinde ileri sürülen "değişim miktarı $\leq$ eşik değer" ve "değişim miktarı > eşik değer" ölçütüne göre, Şekil 1'de gösterilen ağaç diyagramı ile takdim edilmiştir. Burada mevzubahis edilen eşik değer terimi, hacimsel olarak boyutlarda oluşan değişim miktarının kabul edilebilir üst sınırını ifade ederken, kıyaslanabilir bir ölçüt olarak, numunelerin bütün boyutlarını ihtiva eden hacimsel boyut farklılaşmasının daralma ve genişleme deneyleri öncesindeki ölçülere göre gerçekleşen hacimsel boyut değişiminin miktarını yansıtmaktadır.

Bu çerçevede, Şekil 1'de gösterilen ağaç diyagramı, boyutsal kararlılık açısından daralma ve genişleme deneylerine tabi tutulduktan sonra tesadüfi olarak seçilen numunelerin ön işlemli oluşları ve eşik değere istinaden nasıl bir boyut değişimi gösterdiklerine göre düzenlenmiştir. Söz konusu ağaç diyagramının oluşturulmasına dayanak teşkil eden gözlemsel ve deneysel veri aç1lımına göre; a) rastgele seçilen 300 numunenin \%40'ının genişleme şeklinde boyutlarının değiştiği gözlemlenmiş olup bunların \%75'inin gözenek doldurma işlemiyle hazırlanmamış olanların oluşturduğu görülmüş̧ür, b) daralma oluşan numunelerin \%20'sinin ön işlem olan gözenek doldurma ile muamele edilmiş oldukları görülmüştür, c) boyutlarında genişleme gerçekleşen numunelerdeki boyut farklılaşmasının, hazırlık içermeyenlerin \%30'unda eşik değerden büyük olduğu, muamele edilmiş olanların ise \%70'inde eşik değerden küçük olduğu görülmüştür, ç) boyutlarında daralma meydana gelen numunelerdeki boyut farklılaşmasının, hazırlık içermeyenlerin \%25'inde eşik değerden büyük olduğu, muamele edilmiş olanların ise \%50'sinde eşik değerden küçük olduğu görülmüşsür.

Şekil 1. Eşik Değer Bağlamında Gerçekleşen Daralma ve Genişleme Mevcudiyeti

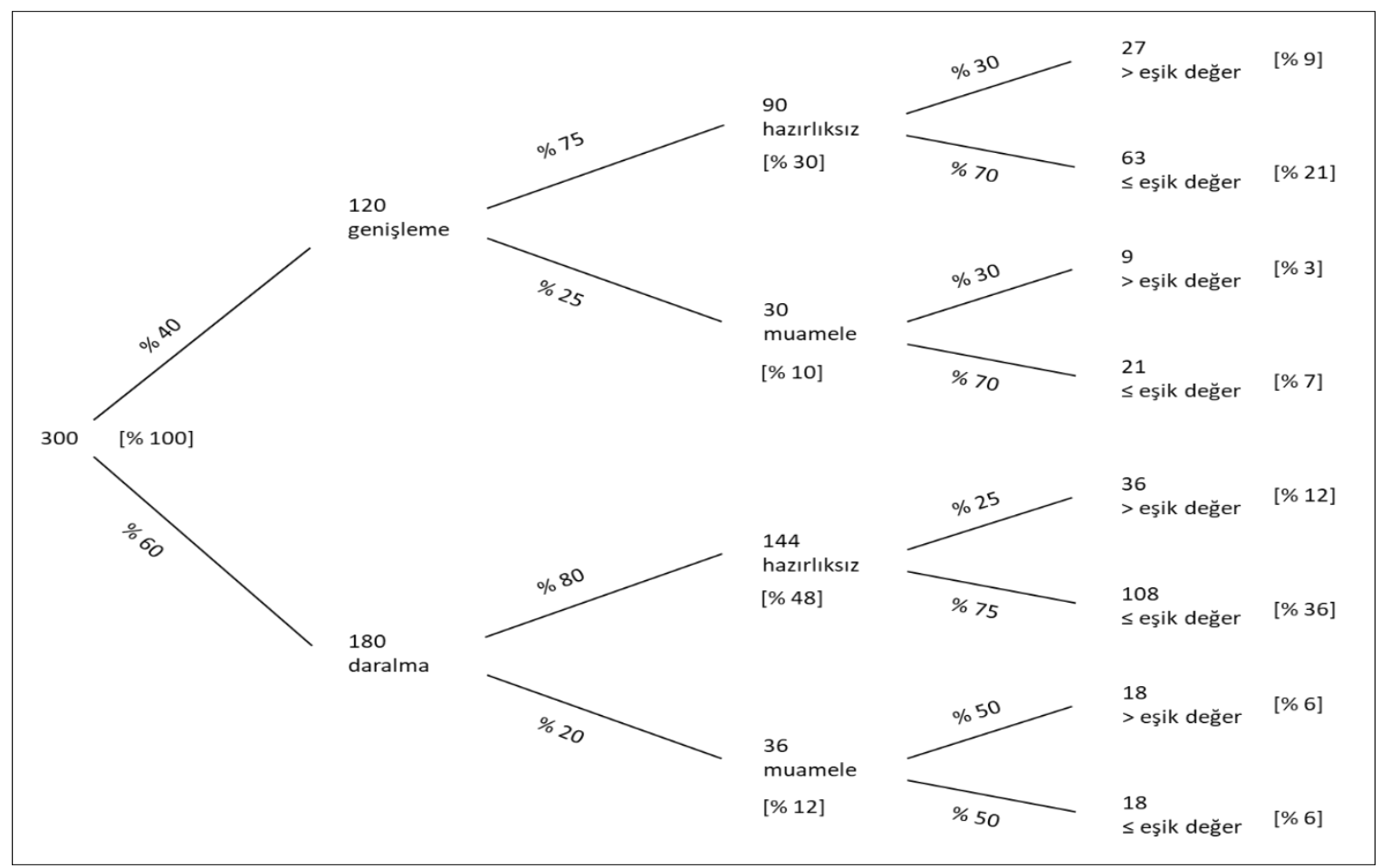




\section{TÜRKIYE MESLEKI VE SOSYAL BILIMLER DERGISi}

Mevcut denekler arasından rassal olarak seçilen numunelerin, gözenek doldurma işlemiyle hazırlanıp hazırlanmadıklarına bağlı olarak eşik değer nezdinde ortaya koydukları boyutsal kararlılık durumu, daralma ve genişleme değişimleri itibariyle Şekil 1'de oluşturulan ağaç diyagramı çerçevesinde, koşullu olasılık hesaplamaları ile aşağıdaki gibi değerlendirilmiştir.

Bir numunenin hazırlama işlemi yapılmamış olduğu için boyutlarında genişleme gerçekleşmiş olanlardan biri olması olasılı $\breve{1}, 90 /(90+144)=0,385$ (veya \%38,5) olarak belirlenirken, daralma gerçekleşenlerden biri olması olasıllı̆ ise, 144 / $(144+90)=0,615$ (veya \%61,5) olarak belirlenmiştir.

Rastgele seçilen hazırlıksız bir numunenin eşik değerden küçük miktarda genişlemiş olması olasılığı, $63 /(63+108)=0,368($ veya $\% 36,8)$ ve daralmış olması olasılığ 1 ise, $108 /(108+63)=0,632$ (veya $\% 63,2$ ) olarak tespit edilirken, söz konusu numunenin eşik değerden büyük miktarda genişlemiş olması olasılığı $27 /(27+36)=0,429$ (veya \%42,9) ve daralmış olması olasılığ ise, $36 /(36+27)=$ 0,571 (veya $\% 57,1$ ) olarak tespit edilmiştir.

Bir numunenin muamele edilmiş olmasına rağmen boyutlarında daralma oluşmuş numunelerden biri olması olasılığ1, $36 /(36+30)=0,545$ (veya \%54,5) olarak hesaplanırken, genişleme oluşmuş olanlardan biri olması olasıllı̆ 1 ise, $30 /(30+36)=0,455$ (veya \%45,5) olarak hesaplanmıştır.

Rastgele seçilen muamele edilmiş bir numunenin eşik değerden küçük miktarda daralmış olması olasılığ $, 18 /(18+21)=0,462($ veya $\% 46,2)$ ve genişlemiş olması olasılığı ise, $21 /(21+18)=0,538$ (veya \%53,8) olarak hesaplanırken, söz konusu numunenin eşik değerden büyük miktarda daralmış olması olasılığı $18 /(18+9)=0,667($ veya \%66,7) ve genişlemiş olması olasılığı ise, $9 /(9+18)=$ 0,333 (veya $\% 33,3$ ) olarak tespit edilmiştir.

\subsection{Boyutsal Kararlılık Sağlama Süreci}

Yukarıda açıklanan gözlemsel ve deneysel veriler eşliğinde koşullu olasılık yaklaşımıyla bakıldığında, neticesi itibariyle biri diğer(ler)ine bağlı biçimde ortaya çıkan olaylar veya durumlar bağlamında, ahşap malzemede boyutsal kararlılı̆̆ sağlamak gayesiyle gerçekleştirilecek iş ve işlemlerin, Şekil 2'de genel hatlarıyla örneklenen etki diyagramı çerçevesinde yapılabileceği söylenebilir.

Şekil 2. Boyutsal Kararlılık Sağlama Yolları

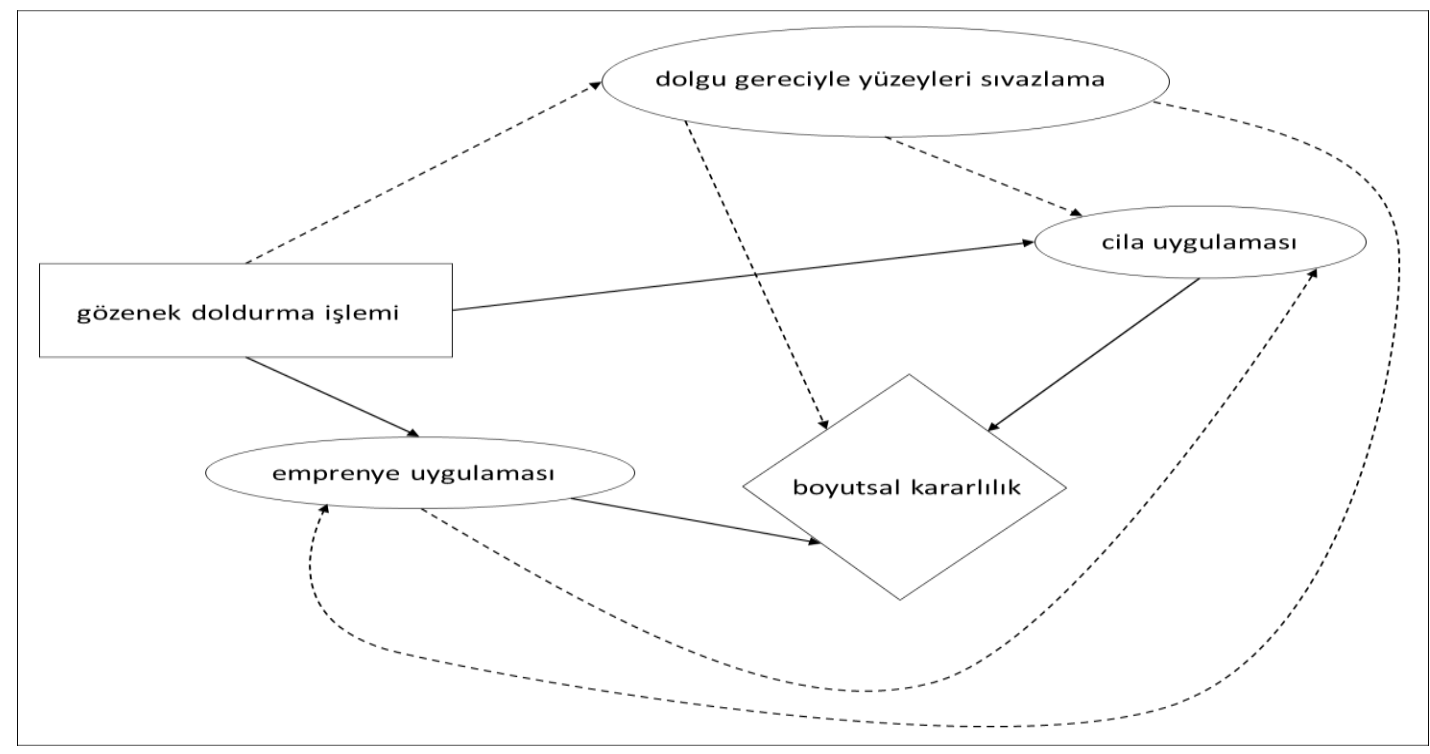

Şekil 2'de gösterilen etki diyagramında, "gözenek doldurma işlemi” boyut değişmezliği amacıyla ortaya koyulan karar olup "dolgu macunuyla yüzeyleri sıvazlama" ve "cila uygulaması" veya "emprenye uygulaması" eylemleri ile "boyutsal kararlılık" sonucuna ulaşılmak için izlenecek yollar 


\section{TÜRKIYE MESLEKI VE SOSYAL BILIMLER DERGISI}

Türkiye Mesleki ve Sosyal Bilimler Dergisi, Aralık 2021, Yıl: 3, Sayı: 7, 74-81

Journal of Vocational and Social Sciences of Turkey, Dec 2021, Year: 3, No: 7, 74-81.

örneklenmektedir. Burada iş akışı çizgilerle gösterilirken, dolu çizgiler eylemin mutlaklığını, kesikli çizgiler ise önerilen eylemin (ikinci seçenek olarak) muhtemelen yapılabileceğini göstermektedir.

\section{SONUÇ}

Ahşap malzemenin daralma ve genişleme zemininde hacimsel bakımdan boyut değişmezliğine temellenen boyutsal kararlılığı, gözenek doldurma işlemi ekseninde gözlem ve deneylere dayalı sıralı bir süreç olarak incelenmiş ve boyutlarda gerçekleşen değişimin (ve ölçümlenen değiş̧mezliğin) niceliği, rastgele seçilmiş numunelere ilişkin hacimsel daralma ve hacimsel genişleme verileriyle oluşturulan ağaç diyagramıyla görselleştirilerek, koşullu olasılık yaklaşımıyla değerlendirilmiştir.

Bu çalışmada, birbirleriyle ilişkili durumlara bir örnek teşkil etmesi bakımından, gözenek doldurmayla muamele edilerek veya bundan muaf tutularak gerçekleştirilen hazırlık süreci nezdinde gerçekleşen boyutsal kararlılık mevcudiyetine yönelik öngörmelerin, neden-sonuç bağdaştırmasına bir dayanak teşkil etmek üzere, istatistiki açıdan koşullu olasılık hesaplamalarıyla yapılabildiği görülmüştür.

Ayrıca, elde edilen gözlemsel ve deneysel veriler, hem yoğunluğu fazla (gözenekliliği az) hem de yoğunluğu az (gözenekliliği fazla) ahşap malzemenin daralma ve/veya genişleme durumu itibariyle boyutsal kararlılık bakımından naif bir içselliğe sahip olduğunu göstermiştir. Bu sonuç, (Kollmann ve Cote (1968), Bozkurt ve Göker (1987), Tsoumis (1991) gibi ahşap malzeme fiziksel özellikleri alanında çalışmalar yapmış araştırmacılar önde gelmek üzere) ahşap bilimi ve teknolojisi literatüründe takdim edilen verisel bilgi ve kuramsal açıklamalar ile uyumludur. Nihayetinde, ahşap malzemenin lif doygunluğu noktası altında ortalama \%12 rutubet miktarı içerecek şekilde kurutulması, hacimsel daralma veya hacimsel genişleme ihtimaline karşı boyutsal kararlılığ pekiştirmeyi sağlayan temel uygulamadır. Buna ilaveten, boyut değişimini önleyen ya da sınırlandıran koruyucu maddelerle ahşap malzemenin emprenye edilmesi ve/veya gözenek doldurma işlemiyle bütünleşik üst yüzey işlemlerinden geçirilmesinin, hacimsel boyut değişmezliğinin göstergesi olan boyutsal kararlılığın (ahşabın kullanım amacı ve kullanılma yerine göre uyarlanmasını öngören metodik yaklaşımlara ve işlemsel faaliyetlere bağlı olarak) hedeflendiği gibi temin edilebilmesine yardımcı olacağı açıktır.

\section{KAYNAKCA}

Bozkurt, A. Y. ve Göker, Y. (1987). Fiziksel ve Mekanik Ağaç Teknolojisi. İstanbul: İstanbul Üniversitesi Orman Fakültesi Yayınları, Yayın No: 3445/388.

Demirhan, H. ve Hamurkaroğlu, C. (2016). İstatistiksel Yöntemlere Giriş. Ankara: Hacettepe Üniversitesi Basımevi.

Kobu, B. (1987). Endüstriyel Kalite Kontrolu. İstanbul: İstanbul Üniversitesi İşletme Fakültesi Yayınları, Yayın No: $3425 / 182$.

Kollmann, F. F. P. ve Cote, W. A. (1968). Principles of Wood Science and Technology. I: Solid Wood. Berlin: Springer-Verlag.

Sönmez, A. (2000). Ağaçişlerinde Üst Yüzey İşlemleri. 1: Hazırlık ve Renklendirme. Ankara: Çizgi Matbaacilik.

Şanıvar, N. (1978). Ağaçişleri Üst Yüzey İşlemleri. İstanbul: Milli Eğitim Basımevi.

Tsoumis, G. (1991). Science and Technology of Wood: Structure, Properties, Utilisation. New York: Van Nostrand Reinhold.

Usta, İ. (2016). "Ahşap Üzerine Betimlemeler: Kültürlerarası Etkileşim Aracı Olan Ahşabın "Değerli bir Nesne” Olarak Kabul Edilip Özümsenmesi (Lifli ve Gözenekli Yapısıyla Ahşap Mükemmeldir)”, Yapı Dünyası, Temmuz/Ağustos (244-245), 8-16.

Usta, İ. (2018). Depictions on Wood: Acceptation and Internalization of Wood, which is an intercultural interaction tool, as "A Valuable Object" (Wood is the Material of Endless Possibilities). The 49th Annual Meeting of the International Research Group on Wood Protection (29 April-03 May 2018, Johannesburg, South Africa), Document No: IRG/WP 18-40837. 